\title{
Security upon moving into a new library building
}

\author{
By Patricia A. Robles
}

\section{How to protect your library's materials against loss or theft}

n January 3, 1994, California State University, Bakersfield (CSUB) opened its new $\$ 22$ million library facility, the Walter $W$. Stiern Library. At 150,000 gross square feet on five floors, it is the largest building on the Bakersfield campus. Instructional Television (ITV) and Media Services are also located in this building. On the lower level there are six computer rooms equipped with more than 200 microcomputers and printers available for student use. The library is a modern electronic information center which includes a state-ofthe-art electronic reference area. It is also extensively cabled for network access throughout the building.

\section{Background}

The move into the newly built Stiern Library occurred during the fall quarter break in December 1993, since no classes were scheduled. Traffic is traditionally very light with few people on campus during this time. The goal was to have the library open and operational on the first day of the winter quarter, January 3, 1994.

When the move began, the building was not yet completed. Various contractors were still working on such projects as installing shelving and the building's telecommunications systems. Library staff prepared for the move while other CSUB personnel moved items such as the equipment and furniture belonging to the Media Services and Computer Services offices into the new facility. A professional library moving company transferred the library's book col- lections, computers and other equipment, and the contents of offices. The movers, therefore, had to compete with the contractors who were working on their respective projects, as well as working around incoming deliveries of furniture and equipment and the comings and goings of authorized library and campus personnel.

Clearly, in a move of this magnitude, with millions of dollars of inventory, the library had to establish a set of procedures in order to protect this valuable property.

\section{Liferature review}

A review of the literature indicates a wealth of literature on the physical moving of a library into a new building; however, security during a move, in most instances, is addressed only briefly, if at all. Despite the brevity, the authors clearly indicate that the security of the collection must be of prime concern. Tucker further states that "it is rather ironic that we spend thousands of dollars to install a security system to protect our materials and then on move day throw the doors wide open to any and all."

\section{Procedures}

Several months before the start of the move, the director of libraries asked that I take over the responsibility of security from the facilities coordinator, who was responsible for various other move-related projects. During the earlier discussions, two areas of concern were identified:

1) Traffic considerations. The campus historically experiences light traffic during the fall quarter break period; most of the people around are CSUB staff arriving and leaving work. It was recommended, then, that no specific needs 


\section{"It is rather ironic that we spend thousands of dollars to install a security system to protect our materials and then on move day throw the doors wide open to any and all."}

identification would be challenged. If a badge could not be produced, an officer would be called.

- Entrance security personnel were instructed that no one was to be permitted to exit the Stiern Library with any equipment or books, whether they had a pass or not. Individuals attempting to leave would be stopped until verification of their authorization to remove the items was confirmed

for barricading roadways or sidewalks were warranted at that time.

2) Security considerations. The more important of the two concerns was the need to develop a procedure that would ensure that unsecured library property, especially expensive equipment such as computers, was not improperly removed from either the old or new library during the confusion that results in such a move. The basic recommendations were:

- Access badges be required of all people entering and exiting either building.

- Sufficient student assistant staffing would be hired for each of the entrances where books and equipment were being moved out of one building and into the other. These students, most of whom had prior experience in Public Safety, would ensure that anyone not wearing a badge would not enter either building.

- These students would be issued two-way radios for direct contact with Public Safety dispatch should a problem arise.

These general recommendations were established prior to my assuming responsibility of this project. My charge, then, was to refine further the library's needs within this framework in cooperation with Public Safety, implement the plan and procedures, and facilitate security, as needed, once the move began. The following details were approved and implemented:

- Those entrances to be used by staff, movers, and vendors were to be staffed from 7:00 a.m. to 7:00 p.m., Monday through Saturday, by Public Safety personnel.

- No one would be permitted entrance into either library building unless he or she had been issued and were wearing one of the two colorcoded, designated passes (yellow for staff, blue for vendors)

- Relief/roving security personnel were instructed to question any individuals they observed inside either library building not wearing a pass. Individuals without the proper by one of the four coordinators: myself, the library director, the facilities coordinator, or the media services director, preferably in that order.

- Security staff would be equipped with radios for communication.

- Security personnel would nor leave their posts unattended for any reason without authorized relief. They were not to be used for any detail or other work request without authorization from the Public Safety officer in charge, or one of the designated coordinators.

\section{Considerations}

Buildings. First, in order to address our student staffing needs, a decision needed to be made about how many and which entrances would be used for the move. With a potential for more than ten combined entrances in both libraries, a total of three entrances were used and, therefore, staffed during the move. All other doors remained locked. At the old library, the main entrance was the only one used. At the Stiern Library, two entrances were used mainly, but others were used when needed. When an entrance other than the two main ones was used, the relief/roving security person staffed the auxiliary entrance.

Student workforce. Once the access points and times of operation were finalized, it was determined there would be four persons working each shift - one at each of the entrances of the two buildings, and a relief person who would roam both buildings and relieve the others as needed. Each shift was six hours.

The hiring and scheduling of the students was handled entirely by the Pubic Safety Office. Fourteen students were hired specifically for this project and all had prior experience working for the Public Safety Office but none had worked in the library. After checking in with the Pubic Safety Office, the students reported directly to me. 
People. The move was not an isolated occurrence in which only library personnel were involved. Well over one hundred CSUB employees, including administrators, staff, and students, actively participated in the move. Media Services, Instructional Television, and the Instructional Electronic Tech Center offices were moving permanently into the Stiern Library building. The staffs of the Computer Services, Plant Operations, Procurement, and Telecommunications offices also needed access to provide their respective services as required. Also, there were various contractors working in the Stiern Library, as well as numerous outside vendors who delivered new furniture or equipment, and/or whose services were required to make the library operational.

Identification. As the university's newest and largest facility, the Stiern Library caused a lot of excitement on campus and in the community. Keeping out curiosity seekers was something the library needed to be prepared for. Also, because of the large number of people involved with the move, some identification procedure was clearly needed to keep unauthorized persons from wandering around the new building.

Badges imprinted with the CSUB Library and numbered sequentially were used as identification. Each badge was assigned to a particular individual with the embossed number crossreferenced to his or her name. Staff members wore yellow passes, vendors and visitors were assigned blue ones. CSUB staff were responsible for their own badges throughout the entire move; vendors' and visitors' badges were issued as needed and were returned at the end of the day.

In simplest terms, the procedure was "no badge, no access, no exceptions."

Communications. Since telephones were not yet operational in the Stiern Library, there was no direct telecommunication between students and library personnel. The students were given two-way radios to communicate with the Public Safety Office. Each of the four coordinators had a portable cellular phone. To communicate, the students radioed the campus' Public Safety dispatcher who then called me (or another coordinator if I was not there) on the cellular phone. Serving as the intermediary, the dispatcher relayed information between us.

\section{Reflections and recommendations}

- Be visible. With lots of activities hap- pening simultaneously, it is important to stay visible, flexible, and patient. If telephones are not operational, it is even more critical to be visible. We quickly discovered that using the campus dispatcher as the intermediary was not very effective. As a result, I spent considerable amounts of time floating between both buildings keeping in close contact with the students, the other coordinators, and library personnel.

- Use two- or four-hour work shifts. The primary task of security-monitoring the flow of materials entering and leaving the buildingswas quite monotonous, which may have contributed to scheduling problems that began occurring in the later stages of the move. Some students did not show up for work, others were late or left early. The six-hour shift was too long for the task at hand.

- Involve library personnel. Using library students and staff as part of the security force would have been a better idea than using only Public Safety's student assistants. The move was chaotic at times and staff anxiety was evident. Besides serving as a calming effect, using library staff would have been more beneficial to the library. The library staff is more familiar with fellow employees (and the departments they work in), and the library would have saved money since the staff was already getting paid to be there, instead of having to pay additional salaries for the Public Safety Office's student assistants. For maximum effectiveness, however, only interested library personnel should be

\section{Feature your collection on the cover of C\&RL News}

CGRL News wants to feature aesthetically pleasing photos of items from library collections on its covers. If you have material in your library's collections that you think would make an attractive CERL Neu's cover, please send us a photograph or a color photocopy and a brief description of the item and the collection. Photos may be either color or black and white and should be $5^{\prime \prime} \times 7^{\prime \prime}$ or $8^{\prime \prime} \times 10^{\prime \prime}$. Illustrations with a vertical orientation work best. Materials submitted will become the property of CERL Neus and cannot be acknowledged. Send to: CERL News Covers, 50 E. Huron St., Chicago, IL 60611 . 
asked to participate in a move. Those not interested may resent the additional responsibility. Also, the move occurred near the Christmas holidays when many staff members were on vacation and, thus, not available. Using staff from both the library and Public Safety could have made security operations run more smoothly.

- Personalize the identification system used as much as possible. Badges worn by staff were often lost or forgotten; some staff resented having to wear one, while others lent their badges to their colleagues even though the passes were supposed to be nontransferable. Also, as long as a person wore a badge, he or she was rarely challenged by security personnel. While there is no way to avoid completely the problems we encountered using the badge numbering system, using individual names rather than numbers on the badges would have been much more effective. Staff would not have been as likely to let others use their badges, plus the security force could have learned the names of the staff, thus becoming more familiar with library personnel. If money and time were not concerns, the ideal option would have been to use picture ID cards such as those used in hospitals and other private sector operations.

\section{Conclusion}

The move from the old library building to the Stiern Library facility went exceptionally well. The library opened as scheduled with book collections, equipment and furniture, and office belongings in place. Overall, the security measures implemented for the move were successful; only one computer terminal could not be accounted for among the millions of dollars of inventory that was relocated to the Stiern Library facility.

Computers, CD-ROMs, and expensive video equipment are a vital component of today's libraries, and, therefore, much more costly to replace. In planning and implementing security for a move to a new facility, safeguarding library property should be the highest priority. Involving library personnel in the move as much as possible should come next.

\section{Notes}

1. Dennis C. Tucker, From Here to There: Moving a Library (Bristol, Ind.: Wyndham Hall Press, 1987).

A NEW DOCUMENT DELIVERY SERVICE FROM THE AMERICAN INSTITUTE OF PHYSICS AND EBSCOdOC

ARTICLES IN PHYSICS gives you immediate access to more than 30,000 scientific and technical publications from AIP, its Member Societies, and other leading scientific publishers worldwide.

Articles In Physics is also an excellent source for material in disciplines other than the physical sciences. Backed by EBSCOdoc's extensive collection and its worldwide resources, researchers and librarians around the world can obtain articles rapidly via mail, fax, or Internet fax. Turnaround time for in-house titles is 24 hours.

\section{A L L T O L L - F RE E $800-480$ - P H Y S} international +01-415-259-6002 fax +01-415-259-6044 e-mail articles@aip.org URL: http://www.aip.org/articles.html OR WRITE TO: Articles In Physics - 1722 Gilbreth Road • Burlingame, CA 94010 